Note

\title{
Resistance to Cationic Surfactants and Some Other Agents of Escherichia coli Recombinants with an Abundant Number of Genes Encoding Drug Efflux Pump
}

\author{
SHU ISHIKAWA, YOSHINOBU MATSUMURA, AND TETSUAKI TSUCHIDO* \\ Department of Biotechnology, Faculty of Engineering, Kansai University, \\ Yamate-cho 3-3-35, Suita 564-8680, Japan
}

Received 30 October 2001/Accepted 21 November 2001

\begin{abstract}
In order to investigate the contribution of the multidrug efflux pumps to cellular resistance to a variety of agents including cationic surfactants, we cloned genes of major drug efflux pumps of Escherichia coli and transformed strain JM109 with plasmids encoding those genes. In emrAB-, mdfA- and emrE-recombinants, the resistance to carbonylcyanide-m-chlorophenylhydrazone (CCCP), chloramphenicol, and paraquat, respectively, was increased compared to their parent bearing pUC18. Also, in $m d f A$ - and emrE-recombinants, the resistance to cetyltrimethylammonium bromide (CTAB) was increased. However, no significant effects of abundant numbers of emrD and envCD could be observed on resistance to agents examined.
\end{abstract}

Key words: Multidrug efflux pump/Cationic surfactant resistance/E. coli.

Surfactants as amphipathic compounds have been utilized in a variety of fields, such as chemical, pharmaceutical and food industries, hospitals, homes, and environments for cleaning, emulsification, solubilization, moisturizing and so on (Schwartz and Perry, 1979). In particular, cationic surfactants have antimicrobial activity (Hugo and Russell, 1992; Schwartz and Perry, 1979) and are therefore widely used in hospitals and food industries as disinfectants or sanitizers. As for the mode of action, they have been reported to disrupt cell membranes (Scharff and Maupin, 1960), interrupt protein functions (Putnam, 1948), release intracellular $\mathrm{K}^{+}$and other constituents (Cabral, 1993; Sakagami et al., 1989), inhibit cellular respiration (Majtan et al., 1995) and induce cell autolysis (Cho et al., 1990; Tsuchido et al., 1990). However, several investigators have isolated so far cationic surfactant resistant-bacteria from a variety of niches (Heir et al., 1995, 1998 and 1999; Kücken et al., 2000; Lemaitre et al., 1998; Littlejohn et al., 1992;

*Corresponding author. Tel: +81-6-6368-0880, Fax : +816-6388-8609
Nagai et al., 1996; Sakagami et al., 1989).

Major ways that bacterial cells acquire drug resistance are as follows: i) inactivation of the drug, ii) characteristic or quantitative change of the target of the drug, iii) depression of drug permeation and iv) active drug efflux (Davies, 1994). Among these ways, drug efflux from cells has recently been actively investigated and many membrane translocators have been found as efflux pumps. Their function is known to confer multidrug resistance to bacterial cells (Lewis, 1994; Nikaido, 1994 and 1996). Such drug efflux pumps can extrude a variety of agents, including antibiotics, surfactants, oxidative phosphorylation uncouplers, and oxidants from cells. Lacroix et al. (1996 and 1995) have found that an acrB-like gene confers not only multiple antibiotic resistance but also multiple surfactant resistance on Salmonella typhimurium cells. Several investigators have also reported that overproduction of drug efflux pumps increases cellular resistance to various agents including surfactants (Edgar and Bibi, 1997; Jack et al., 2000; Neyfakh et al., 1991). We have also isolated and characterized a cationic surfactant resistant strain of 
Escherichia coli and found that the strain has an altered cell envelope compared to its parent strain (Ishikawa et al., 2002).

In this study, to investigate a possible contribution of increased numbers of efflux pump genes to the cellular resistance to a variety of agents including cationic surfactants, we cloned genes of major drug efflux pumps referred to in GenBank, emrAB (AE000152), emrD (AE000445), mdfA (cmr; AE000186), emrE (mvrC; AE000160) and envCD (acrEF; AE000405), from the chromosomal DNA of $E$. coli, and then examined how much efflux pump gene-recombinants of $E$. coli increase their resistance to cationic surfactants and some other agents.

Genes of drug efflux pumps of $E$. coli including their original promoters and terminators amplified by the PCR method were cloned in multi-cloning sites of pUC18/19 or pHSG575 (Table 1). Chromosomal DNA of E. coli OW6 (Pro-) (Kitagawa et al., 2000) as a template and primer sets designed from the $E$. coli genome sequence were employed (Table 2). Strain JM109 (recA1, endA1, gyrA96, thi, hsdR17, supE44, relA1, $\triangle$ (lac-proAB)/F' $\left[\operatorname{traD} 36\right.$, pro ${ }^{+}$, lacl $^{\circ}$, lac $\triangle M$ 15]) (Sambrook et al., 1989) was used as a host strain. Recombinants were cultivated in LB medium $(\mathrm{pH} 7.4$ ), consisting of $10 \mathrm{~g}$ bacto tryptone (Difco Laboratories, Detroit, USA), $5 \mathrm{~g}$ yeast extract (Difco Laboratories), and $5 \mathrm{~g} \mathrm{NaCl}$ per liter, at $37^{\circ} \mathrm{C}$ with shaking at $120 \mathrm{rpm}$ with or without an antimicrobial agent added. The minimum growth inhibitory concentration (MIC) of agents was determined by cultivation using LB medium with shaking at $37^{\circ} \mathrm{C}$ for $18 \mathrm{~h}$ as previously described (Ishikawa et al., 2002). Membrane proteins were extracted by sonication following the method of Fukuoka et al. (1991), and analyzed by SDS-PAGE (Laemmli, 1970). The proportion of plasmid retention in the host strain was determined as follows. After a portion of the overnight culture was di-

TABLE 1. Recombinant plasmids employed in this study.

\begin{tabular}{llll}
\hline \multicolumn{1}{c}{ Plasmid } & \multicolumn{1}{c}{ Description } & Substrates of cloned drug efflux pump & \multicolumn{1}{c}{ Source or Reference } \\
\hline pUC18/19 & High-copy-number vectors, $\mathrm{Ap}^{\prime}$ & & Yanisch-Perron et al., 1985 \\
pHSG575 & Low-copy-number vector, $\mathrm{Cm}^{r}$ & & Takeshita et al., 1987 \\
pEAB1906 & pUC19 carrying emrAB & CCCP, phenylmercury acetate, NAX & This study \\
pED1906 & pUC19 carrying emrD & CCCP, phenylmercury acetate & This study \\
pMA1806 & pUC18 carrying $m d f A$ & Cm, Tc, Em, BC, EB, and others & This study \\
pEE1806 & pUC18 carrying emrE & Lipophilic cations (PQ, EB, TPP) & This study \\
pECD4806 & pHSG575 carrying envCD & Em, Tc, Ap, SDS, CV, and others & This study \\
\hline
\end{tabular}

${ }^{a}$ Substrates were referred to in reports by Nikaido (1994 and 1996). Abbreviations: NAX, Nalidixic acid; $\mathrm{Cm}$, chloramphenicol; Tc, tetracycline; Em, erythromycin; $\mathrm{BC}$, benzalkonium chloride; CV, crystal violet; $\mathrm{EB}$, ethidium bromide; $\mathrm{PQ}$, paraquat; TPP, tetraphenylphosphonium; Ap, ampicillin; SDS, sodium dodecyl sulfate.

TABLE 2. Oligonucleotibe primers used to amplify MDR genes.

\begin{tabular}{|c|c|c|}
\hline Gene & Name $^{a}$ & Sequence of oligonucleotide (5' to $\left.3^{\prime}\right)^{b}$ \\
\hline \multirow[t]{2}{*}{ emrAB } & emrAB-U & CGTCTTTGCATGCACATGCA (Sph I) \\
\hline & emrAB-D & GAAAGAGGGATCCATACCCT $($ BamH I) \\
\hline \multirow[t]{2}{*}{$e m r D$} & emrD-U & TGCACAAaAGCTtGCAACAG (Hind III) \\
\hline & emrD-D & CCCAGGACTGCAGCCGGAGC (Pst I) \\
\hline \multirow[t]{2}{*}{$m d f A$} & mdfA-U & AAAAATCGtCgACGAGATCA ( $\mathrm{Sa} / \mathrm{I})$ \\
\hline & mdfA-D & CGAACACaAGcTTGACGACC (Hind III) \\
\hline \multirow[t]{2}{*}{ emrE } & emrE-U & CGATGCCETGCAGATGGCGC (Pst I) \\
\hline & emrE-D & CTGATTGTGCATGCTTTCCT (Sph I) \\
\hline \multirow[t]{2}{*}{ envCD } & envCD-U & ATGTCGTTGAGCGTCGaCTTGCTTACGCCA ( $\mathrm{Sa} / \mathrm{I})$ \\
\hline & envCD-D & ATTGTAAAAATAcTGcAGGGAGCGGGAACT (Pst I) \\
\hline
\end{tabular}

${ }^{a} U$ and $D$ indicate primers for the upstream region and downstream region, respectively.

${ }^{b}$ Restrection sites were indicated as underlined letters, and small letters indicate mutation introduced. 
luted, cells were spread on the LB agar plate with or without the marker antibiotic. Then, plates were incubated at $37^{\circ} \mathrm{C}$ for $16 \mathrm{~h}$. The index of plasmid stability was calculated as a ratio of colony forming units on the antibiotic-containing plate versus that on the plain LB plate.

Recombinants grew in the plain LB medium as did the parental strain bearing pUC18. Percentages of plasmid retention in all recombinants were over $80 \%$, even if recombinants were cultivated in the absence of a plasmid selective marker. This result indicates that each plasmid is highly stable in the host cell, and thereafter recombinants were cultivated without addi-

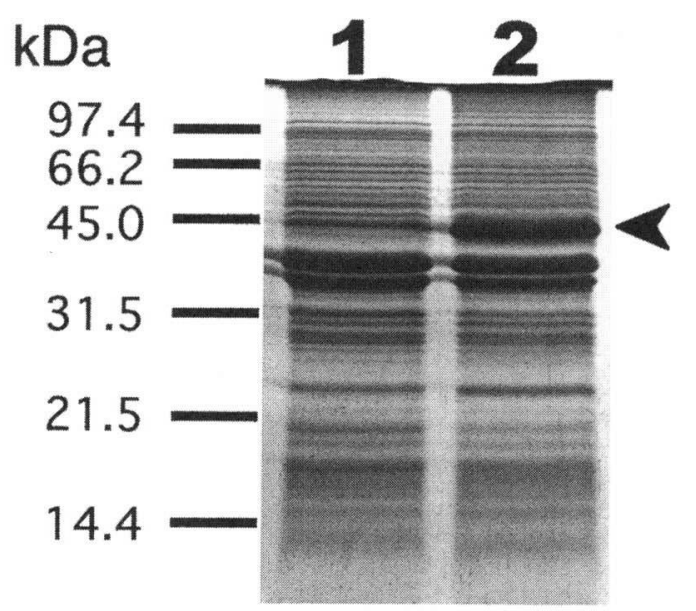

FIG. 1. SDS-PAGE analysis of membrane proteins. Membrane fraction extracted from an overnight culture of strain JM109/pEAB1906 grown in LB medium containing CCCP at a final concentration of $50 \mu \mathrm{M}$. Lane 1: membrane fraction of the parental strain grown in plain LB medium, Lane 2: membrane fraction of JM109/pEAB1906 grown in LB medium containing CCCP. The arrow indicates a signal of EmrA. tion of a plasmid marker when their drug resistance was evaluated.

We examined the overproduction of the products of emrAB genes in JM109/pEAB1906 after cultivation in $\mathrm{CCCP}(50 \mu \mathrm{M})$-containing medium. Though an increase in the signal of EmrB was not found at the position corresponding to a molecular mass of $56 \mathrm{kDa}$, overproduction of EmrA was detected (Fig. 1).

Resistance of efflux pump gene-recombinants to agents as efflux substrates listed in Table 1 was examined by using both the MIC test and the descriptive turbidity monitoring method. The MIC of CCCP for the emrAB-recombinant was twice and that of chloramphenicol for the $m d f A$-recombinant was 7 times as much as that of the parental strain bearing pUC18 (Table 3 ). In the emrD-recombinant, the MIC of CCCP was scarcely increased (Table 3 ). Further, both the emrAB- and $m d f A$-recombinants grew in a medium containing CCCP (100 $\mu \mathrm{M})$ and chloramphenicol (20 $\mathrm{\mu g} / \mathrm{ml})$, respectively, without any delay in growth, whereas their parental strain could not grow under the same conditions (Fig. 2A and B). Although increased resistance to paraquat was not found in the emrE-recombinant when the MIC method was used, a difference in the growth pattern was observed when the turbidity was monitored during the early stages of cultivation. The emrE-recombinant grew in the medium containing paraquat at a final concentration of $50 \mu \mathrm{M}$, whereas the growth of its parental strain was inhibited markedly (Fig. 2C). However, in the envCDrecombinant, we failed to find increased resistance to ampicillin, tetracycline, erythromycin and crystal violet (Table 3 and data not shown), which have been known as efflux substrates (Nikaido, 1994).

To investigate the surfactant resistance of efflux pump gene-recombinants the following agents were

TABLE 3. MICs ${ }^{a}$ of various agents against $E$. coli transformants carrying various drug efflux pump genes.

\begin{tabular}{lcccccccccc}
\hline \multicolumn{1}{c}{ Plasmid } & $\begin{array}{c}\text { Gene } \\
\text { carried }\end{array}$ & $\begin{array}{c}\mathrm{Ap} \\
(\mu \mathrm{g} / \mathrm{ml})\end{array}$ & $\begin{array}{c}\mathrm{Cm} \\
(\mu \mathrm{g} / \mathrm{ml})\end{array}$ & $\begin{array}{c}\mathrm{TC} \\
(\mu \mathrm{g} / \mathrm{ml})\end{array}$ & $\begin{array}{c}\mathrm{CV} \\
(\mu \mathrm{g} / \mathrm{ml})\end{array}$ & $\begin{array}{c}\mathrm{CCCP} \\
(\mu \mathrm{M})\end{array}$ & $\begin{array}{c}\mathrm{PQ} \\
(\mu \mathrm{M})\end{array}$ & $\begin{array}{c}\text { CTAB } \\
(\mu \mathrm{M})\end{array}$ & $\begin{array}{c}\mathrm{BC} \\
(\mu \mathrm{M})\end{array}$ & $\begin{array}{c}\mathrm{CPC} \\
(\mu \mathrm{M})\end{array}$ \\
\hline pUC18 & - & $\mathrm{ND}^{b}$ & 10 & 4 & $>10$ & 150 & $>500$ & 30 & 20 & 20 \\
pEAB1906 & $e m r A B$ & $\mathrm{ND}$ & 10 & 4 & $>10$ & $\mathbf{3 0 0}$ & $>500$ & 20 & 20 & 10 \\
pED1906 & $e m r D$ & $\mathrm{ND}$ & 15 & 6 & $>10$ & $\mathbf{2 0 0}$ & $>500$ & 20 & 20 & 20 \\
pMA1806 & mafA & $\mathrm{ND}$ & $\mathbf{7 0}$ & $\mathbf{6}$ & $>10$ & 150 & $>500$ & 20 & $\mathbf{2 0}$ & 20 \\
pEE1806 & $e m r E$ & $\mathrm{ND}$ & 10 & 4 & $>10$ & 100 & $>\mathbf{5 0 0}$ & 40 & 30 & 20 \\
pHSG575 & - & 18 & $\mathrm{ND}$ & 6 & $>10$ & 150 & $>500$ & 20 & 20 & 10 \\
pECD4806 & envCD & $\mathbf{6}$ & $\mathrm{ND}$ & $\mathbf{6}$ & $>\mathbf{1 0}$ & 150 & $>500$ & 20 & 20 & 20 \\
\hline
\end{tabular}

${ }^{a}$ Bold letters indicate substrate (s) of each efflux pump, and names of drugs are abbreviated as follows; Ap, ampicillin; $\mathrm{Cm}$, chloramphenicol; Tc, tetracycline; CV, crystal violet; $\mathrm{PQ}$, parquat; $\mathrm{BC}$, benzalkonium chloride;

$\mathrm{CPC}$, cetylpyridinium chloride.

${ }^{b}$ Not done; the agent corresponds to plasmid marker. 

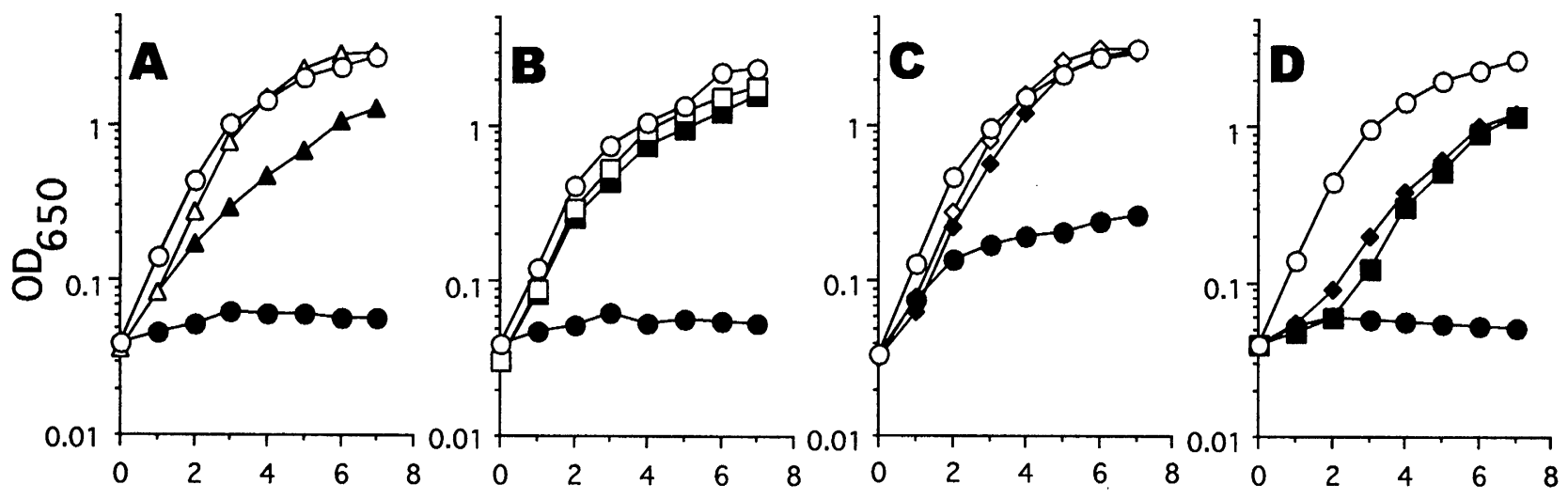

Time (h)

FIG. 2. Growth of $E$. coli JM109 carrying plasmids encoding different efflux pump genes in the presence of $100 \mu \mathrm{M} C C C P$ (A), $20 \mathrm{\mu g} / \mathrm{ml}$ chloramphenicol (B), $50 \mu \mathrm{M}$ paraquat (C) and $15 \mu \mathrm{M}$ CTAB (D). Strain JM109 harboring a plasmid pUC18 (O, O), pEAB1906 $(\triangle, \boldsymbol{\Delta})$, pMA1806 $(\square, \boldsymbol{Q})$, or pEE1806 $(\diamond, \diamond)$, was cultivated in $L$ medium at $37^{\circ} \mathrm{C}$. Closed and open symbols indicate growth in the medium with and without addition of the drug, respectively.

employed: CTAB (Wako Pure Chemical Industries, Ltd., Osaka), benzalkonium chloride (Dojindo Laboratories, Kumamoto), cetylpyridinium chloride (Wako), benzethonium chloride (Wako) as cationic types, and sodium dodecyl sulfate (SDS, Wako) and sodium deoxycholate and 3[(3-cholamidopropyl)-dimethylammonio]-1-propanesulfate (CHAPS, Dojindo Laboratories) as anionic and zwitterionic types. For all surfactants examined, no significant differences in the MIC were observed between each recombinant and its parental strain (Table 3 and data not shown). In the turbidity monitoring, however, the $m d f A$ - and emrE-recombinants grew after a short lag even in the presence of $15 \mu \mathrm{M}$ CTAB, whereas the parental strain did not (Fig. 2D).

It is generally considered that the activity of the drug efflux pump directly corresponds to the degree of cellular drug resistance (Nikaido, 1994 and 1996). In fact, in this study, the $m d f A$ - and emrE-recombinants were demonstrated to have multidrug resistance. However, no marked multidrug resistance was observed in each recombinant tested here. One possible reason may be due to the nature of the host strain JM109 itself. This strain has a full set of genes of drug efflux pumps, including genes used in this study, on its chromosome. We infer that the drug resistance of strain JM109 is relatively high and this high basal resistance may mask an increase in drug resistance mediated by each amplified gene of pump. In fact, when an $a c r A B$ mutant of $E$. coli, which has low basal resistance, is used to clone efflux pump genes, markedly increased resistance has been obtained (Masaoka et al., 2000; Mine et al., 1999; Morita et al.,1998).
Very recently, characterization of knock-out mutants (Sulavik et al., 2001) and overproducing strains (Nishino and Yamaguchi, 2001) of various drug efflux genes in E. coli have been investigated. However, it remains unclear whether and how those genes are involved in the appearance of drug resistant bacteria like those isolated from hospitals or food industries.

We have isolated a CTAB-resistant mutant from $E$. coli and reported that the mutant was multidrug resistant (Ishikawa et al., 2002). We cloned the same sets of drug efflux pumps described here from the mutant and investigated the degree of increased resistance of recombinants having those genes. However, the effect of gene dosage efflux pump genes derived from this mutant were the same level as those derived from the parent strain OW6 (data not shown). In this mutant, therefore, it is suggested that some mechanism other than drug efflux may also work for its multidrug resistance.

Recently, several mutants resistant to sanitizers including cationic surfactants have been isolated and some of them were characterized to possess multiple antibiotic resistant property (Akimitsu et al., 1999; Ishikawa et al., 2002; Tattawasart et al., 1999). This finding predicts a possible risk upon resulting from continuous use of surfactants, that is, the occurrence of multidrug resistant mutants from bacteria inhabiting various niches. Moreover, Miyamae et al. (1998) have reported a norfloxacin-resistant mutant of Bacteroides fragilis isolated spontaneously which increased its resistances not only to several antibiotics but also to CTAB. The cross resistance between sanitizers including surfactants and antibiotics does not seem to be a peculiar phenomenon, since 
bacteria easily acquire multidrug resistance, as exemplified previously (Ishikawa et al., 2002). In the near future, these mutants might become a serious environmental problem in human life. In order to understand the detailed mechanisms of bacterial multidrug resistance, further studies are necessary.

\section{ACKNOWLEDGMENTS}

We thank Akio Miguchi and Hideki Aramaki for technical assistance in part of experiments.

\section{REFERENCES}

Akimitsu, N., Hamamoto, H., Inoue, R., Shoji, M., Akamine, A., Takemori, K., Hamasaki, N., and Sekimizu, K. (1999) Increase in resistance of methicillin resistant Staphylococcus aureus to $\beta$-lactams caused by mutations conferring resistance to benzalkonium chloride, a disinfectant widely used in hospitals. Antimicrob. Agents Chemother., 43, 3042-3043.

Aono, R., Tsukagoshi, N., and Yamamoto, M. (1998) Involvement of outer membrane protein TolC, a possible member of the mar-sox regulon, in maintenance and improvement of organic solvent tolerance of Escherichia coli K 12. J. Bacteriol., 180, 938-944.

Cabral, J. P. (1993) Dodecylguanidine monoacetate (dodine) causes severe membrane damage in Pseudomonas syringae above the critical micelle concentration. J. Basic Microbiol., 33, 219-225.

Cho, H.-Y., Tsuchido, T., Ono, H., and Takano, M. (1990) Cell death of Bacillus subtilis caused by surfactants at low concentrations results from induced cell autolysis. J. Ferment. Bioeng., 70, 11-14.

Davies, J. (1994) Inactivation of antibiotics and the dissemination of resistance genes. Science, 264, 382-388.

Edgar, R., and Bibi, E. (1997) MdfA, an Escherichia coli multidrug resistance protein with an extraordinarily broad spectrum of drug recognition. J. Bacteriol., 179, 22742280.

Fukuoka, T., Masuda, M., Takenouchi, T., Sekine, N., lijima, M., and Ohya, S. (1991) Increase in susceptibility of Pseudomonas aeruginosa to carbapenem antibiotics in low-amino-acid media. Antimicrob. Agents Chemother., 35, 529-532.

Heir, E., Sundheim, G., and Holck, A. L. (1995) Resistance to quaternary ammonium compounds in Staphylococcus spp. isolated from the food industry and nucleotide sequence of the resistance plasmid pST827. J. Appl. Bacteriol., 79, 149-156.

Heir, E., Sundheim, G., and Holck, A. L. (1998) The Staphylococcus qach gene product: a new member of the SMR family encoding multidrug resistance. FEMS Microbiol. Lett., 163, 49-56.

Heir, E., Sundheim, G., and Holck, A. L. (1999) The qacG gene on plasmid PST94 confers resistance to quaternary ammonium compounds in staphylococci isolated from the food industry. J. Appl. Microbiol., 86, 378-388.

Hooper, D. C., Wolfson, J. S., Souza, K. S., Tung, C., Mchugh, G. L., and Swartz, N. (1986) Genetic and biochemical characterization of norfloxacin resistance in Escherichia coli. Antimicrobial. Agents Chemother., 29, 639-644.

Hugo, W. B., and Russell, A. D. (1992) Factors influencing the efficacy of antimicrobial agents. In Principles and Practice of Disinfection, Preservation and Sterilization. 2nd edn., (Russell A. D., Hugo W. B. and Ayliffe G. A. J., ed.), pp. 90-92. Blackwell Science Publications, Oxford.

Ishikawa, S., Matsumura, Y., Yoshizako, F., and Tsuchido, T. (2002) Characterization of a cationic surfactant-resistant mutant isolated spontaneously from Escherichia coli. J. Appl. Microbiol., 92, 261-268.

Jack, D. L., Storms, L. M., Tchieu, J. H., Paulsen, I. T., and Saier, M. H., Jr. (2000) A broad-specificity multidrug efflux pump requiring a pair of homologous SMR-type proteins. J. Bacteriol., 182, 2311-2313.

Kitagawa, M., Matsumura, Y., and Tsuchido. T. (2000) Small heat shock proteins, $\mathrm{IbpA}$ and $\mathrm{IbpB}$, are involved in resistances to heat and superoxide stresses in Escherichia coli. FEMS Microbiol. Lett., 184, 165-171.

Kücken, D., Feucht, H.-H., and Kaulfers P.-M. (2000) Association of qacE and gacE $\triangle 1$ with multiple resistance to antibiotics and antiseptics in clinical isolates of Gramnegative bacteria. FEMS Microbiol. Lett., 183, 95-98.

Lacroix, F. J. C., Avoyne, C., Pinault, C., Popoff, M. Y., and Pardon, P. (1995) Salmonella typhimurium TnphoA mutants with increased sensitivity to biological and chemical detergents. Res. Microbiol., 146, 659-670.

Lacroix, F. J. C., Cloeckaert, A., Grépinet, O., Pinault, C., Popoff, M. Y., Waxin. H., and Pardon, P. (1996) Salmonella typhimurium acrB-like gene: identification and role in resistance to biliary salts and detergents and in murine infection. FEMS Microbiol. Lett., 135, 161-167.

Laemmli, U. K. (1970) Cleaving of structural proteins during the assembly of the head of bacteriophage T4. Nature, 227, 680-685.

Lemaitre, J. P., Echchannoui, H., Michaut, G. Divies, C., and Rousset. A. (1998) Plasmid-mediated resistance to antimicrobial agents among listeriae. J. Food Protect., 61, 1459-1464.

Lewis, K. (1994) Multidrug resistance pumps in bacteria: variations on a theme. Trends Biochem. Sci., 19, 119. 123.

Littlejohn, T. G., Paulsen, I. T., Gillespie, M. T., Tennent, J. M., Midgley, M., Jones, I. G., Purewal, A. S., and Skurray, R. A. (1992) Substrate specificity and energetics of antiseptic and disinfectant resistance in Staphylococcus aureus. FEMS Microbiol. Lett., 95, 259-266.

Majtan, V., Majtanova, L., Hostacka, A., Hybenova, D., and Mlynarcik, D. (1995) Effect of quaternary ammonium salts and amine oxides on Pseudomonas aeruginosa. Microbios, 84, 41-51.

Masaoka, Y., Ueno, Y., Morita, Y., Kuroda, T., Mizushima, T., and Tsuchiya, T. (2000) A two-component multidrug efflux pump, EbrAB, in Bacillus subtilis. J. Bacteriol., 182, 2307-2310. 
Mine, T., Morita, Y., Kataoka, A., Mizushima, T., and Tsuchiya, T. (1999) Expression in Escherichia coli of a new multidrug efflux pump, MexXY, from Pseudomonas aeruginosa. Antimicrob. Agents Chemother., 43, 415417.

Miyamae, S., Nikaido, H., Tanaka, Y., and Yoshimura, F. (1998) Active efflux of norfloxacin by Bacteroides fragilis. Antimicrob. Agents Chemother., 42, 2119-2121.

Morita, Y., Kodama, K., Shiota, S., Mine, T., Kataoka, A., Mizushima, T., and Tsuchiya, T. (1998) NorM, a putative multidrug efflux protein, of Vibrio parahaemolyticus and its homolog in Escherichia coli. Antimicrob. Agents Chemother., 42, 1778-1782.

Nagai, K., Ohta, S., Zenda, H., Matsumoto, H., and Makino. M. (1996) Biochemical characterization of a Pseudomonas fluorescens strain isolated from benzalkonium chloride solution. Biol. Pharm. Bull., 19, 873-875.

Neyfakh, A. A., Bidnenko, V. E., and Chen, L. B. (1991) Efflux-mediated multidrug resistance in Bacillus subtilis: similarities with a mammalian system. Proc. Natl. Acad. Sci. USA, 88, 4781-4785.

Nikaido, H. (1994) Prevention of drug access to bacterial targets: permeability barriers and active efflux. Science, 264, 382-388.

Nikaido, H. (1996) Multidrug efflux pumps of Gram-negative bacteria. J. Bacteriol., 178, 5853-5859.

Nishino, K., and Yamaguchi, A. (2001) Analysis of a complete library of putative drug transporter genes in Escherichia coli. J. Bacteriol., 183, 5803-5812.

Putnam, F. W. (1948) The interaction of protein and synthetic detergents. Adv. Protein Chem., 4, 79-122.

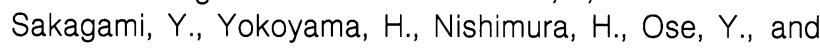
Tashima, T. (1989) Mechanism of resistance to benzalkonium chloride by Pseudomonas aeruginosa. Appl. Environ. Microbiol., 55, 2036-2040.

Sambrook, J., Fritsch, E. F., and Maniatis, T. (1989)
Molecular Cloning: A Laboratory Manual. 2nd ed. Cold Spring Harbor Laboratory, Cord Spring Harbor, NY.

Sampson, B. A., Misra, R., and Benson, S. A. (1989) Identification and characterization of a new gene of Escherichia coli K-12 involved in outer membrane permeability. Genetics, 122, 491-501.

Scharff, T. G., and Maupin, W. C. (1960) Correlation of the metabolic effects of benzalkonium chloride with its membrane effects in yeast. Biochem. Pharmacol., 5, 79-86.

Schwartz, A. M., and Perry, J. W. (1979) Surface Active Agents : Their Chemistry and Technology. Krieger, Huntington.

Sulavik, M. C., Houseweart, C., Cramer, C., Jiwani, N., Murgolo, N., Greene, J., DiDomenico, B., Shaw, K. J., Miller, G. H., Hare, R., and Shimer, G. (2001) Antibiotic susceptibility profiles of Escherichia coli strains lacking multidrug efflux pump genes. Antimicrob. Agents Chemother., 45, 1126-1136.

Takeshita, S., Sato, M., Toba, M., Masahashi, W., and Hashimoto-Gotoh, T. (1987) High-copy-number and lowcopy-number plasmid vectors for lac $Z \propto$-complementation and chloramphenicol- or kanamycin-resistance selection. Gene, 61, 63-74.

Tattawasart, U., Maillard, J. Y., Furr, J. R., and Russell, A. D. (1999) Development of resistance to chlorhexidine diacetate and cetylpyridinium chloride in Pseudomonas stutzeri and changes in antibiotic susceptibility. J. Hosp. Infect., 42, 219-229.

Tsuchido, T., Svarachorn, A., Soga, H., and Takano, M. (1990) Lysis and aberrant morphology of Bacillus subtilis cells caused by surfactants and their relation to autolysin activity. Antimicrob. Agents Chemother., 34, 781-785.

Yanisch-Perron, C., Vieira, J., and Messing, J. (1985) Improved $\mathrm{M} 13$ phage cloning vectors and host strains: nucleotide sequences of the M13mp18 and pUC19 vectors. Gene, 33, 103-119. 